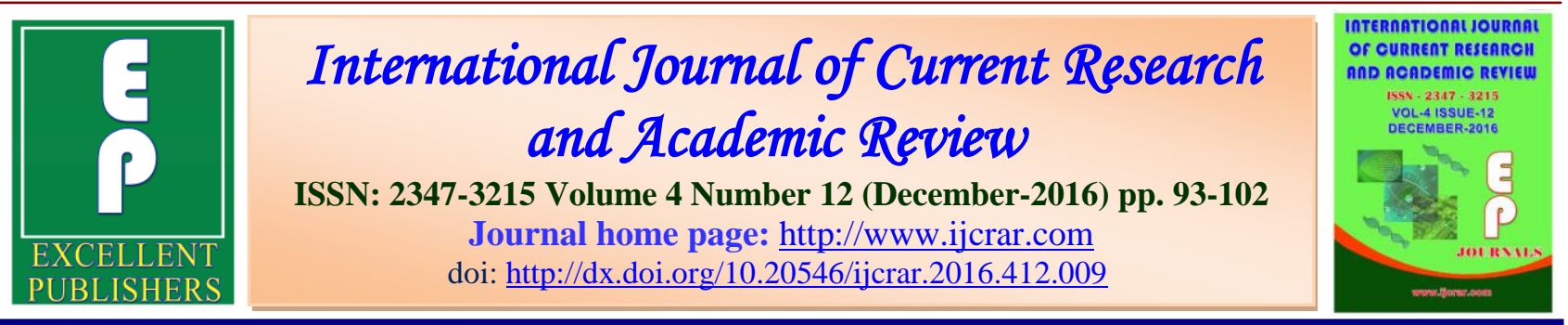

\title{
Yogic Management of Anger in High School Children
}

\author{
T.L. Alaka Mani ${ }^{1 *}$, M.K. Sharma ${ }^{2}$, P. Marimuttu ${ }^{3}$, S.N. Omkar ${ }^{4}$ and H.R. Nagendra ${ }^{5}$ \\ ${ }^{1} \mathrm{Ph} . \mathrm{D}$ Scholar, SVYASA Yoga University, Bengaluru, India \\ ${ }^{2}$ Addl Professor, Department of Clinical Psychology, NIMHANS, Bengaluru, India \\ ${ }^{3}$ Addl Professor, Department of Bio-Statistics, NIMHANS, Bengaluru, India \\ ${ }^{4}$ Chief Research Scientist, Dept Aerospace Engineering, Indian Institute of Science; \\ Bengaluru, India \\ ${ }^{5}$ Chancellor, SVYASA Yoga University; Bengaluru, India \\ *Corresponding author
}

\begin{tabular}{|c|c|}
\hline KEYWORDS & A B $S \mathbf{T} R \mathbf{A} \mathbf{C} \mathbf{T}$ \\
\hline $\begin{array}{l}\text { Yoga, } \\
\text { adolescents, } \\
\text { anger, } \\
\text { schools. }\end{array}$ & $\begin{array}{l}\text { Adolescent anger which is a strong predictor of violence, homicide, road } \\
\text { accidents etc. also has negative impact on academic success and emotional } \\
\text { welling-being. There is a growing consensus among researchers to develop } \\
\text { effective anger management programs for school children. Yoga in schools } \\
\text { which is found to be effective for physical and mental health is assessed in } \\
\text { this study for its efficacy in anger management. Yoga intervention based pre- } \\
\text { post control study ( } \mathrm{n}=187,88 \text { boys and } 99 \text { girls) was carried out in two high } \\
\text { schools for } 4 \text { months with } 2 \text { sessions per week. Yoga sessions were } \\
\text { conducted during academic hours. Anger was assessed using self-reporting } \\
\text { scales and feedback from parents. Authorized tools and software were used to } \\
\text { measure and analyse the data. Significant reduction of angeris observed in } \\
\text { yoga group in both girls and boys with mean score of pre intervention being } \\
46.20 \text { and post intervention } 42.41 \text { achieved at } 99 \% \text { confidence. Marginal } \\
\text { increase in anger is observed in control group girls. Yoga education in } \\
\text { schools is very effective in addressing the issues of anger among high school } \\
\text { children. Future studies are recommended to use physiological parameters of } \\
\text { anger in addition to self-reporting scales. }\end{array}$ \\
\hline
\end{tabular}

\section{Introduction}

Adolescents of today are confronted with a variety of life stressors both at home and school (Kessler, 2007). They establish patterns of behaviour and make lifestyle choices which are likely to influence rest of their life (Catherine, 2010; Kessler, 2010). Adolescent anger which is considered as a health disparity also has life-long impact on individual's physical, psychological and social health and wellbeing (CDD, 2009).

Escalated adolescent anger related issues in schools and colleges across the globe are the 
most serious concerns of parents, educators and the mental health community. Anger is a strong precursor for aggression (Cornell DG, 1999), violence and many other negative conduct and behavioural issues in adolescents (Simona, 2012). Adolescent anger has been associated with devastating social events, adolescent mortality (CDC, 2015) and has rippling effect on major institutions of society. Childhood anger is also a risk factor for adulthood violence and criminal behaviour (Huesmann, 2002).

Adolescent anger has strong relationship with school performance (Munni, 2006), high risk-taking behaviours (Jungmeen, 2015), violent behaviours (Dale, 2009), adjustment scores and negative life events (Colleen, 2014), drug use (Kathryn Puskar, 2008), shame and negative relationships (Coskun, 2009; Jennie, 2011). Significant association is also seen with many mental health disorders such as depression (Pullen, 2015), stress\& coping (Zimmer, 2015), suicidal attempts (Stephanie SD, 2009) selfharm (Beata, 2016). There is a growing consensus among researchers to develop effective anger management programs for school children (Furlong, 2012).

Yoga education in secondary schools is considered feasible, acceptable (Khalsa, 2011; Bethany, 2015) and can be an appropriate scientific approach to maintain mental health among children (Telles, 2012; Hagen, 2014). Studies indicate positive impact of yoga on adolescent cognitive abilities (Chaya, 2012), stress alleviation (White, 2012; Miron Ehud, 2010; Vernon, 2003), personality development (Das, 2016), self-awareness, self-regulation (Donna, 2016), behavioral and emotional maturity (White, 2009).

Further, concept of anger is dealt exhaustively and precisely in the Vedic and
Vedantic texts. In particular Bhagavad-gita (BG) and Patanjali Yoga Sutras (PYS) throw enormous light on anger, its consequences and management. Traditional Scriptures consider anger as an evil virtue which destroys one's personality (BG 2-62, 63). Yoga is all about gaining mastery over mind (PYS 1-2) and advocates chitta prasadanam / emotional intelligence (PYS 1-33). Anger management is promoted in yoga sutras by endorsing ahimsa /non-violence (PYS 2-30, 35), abhyasa / practice \&vairagya / dispassion (PYS 1-12), pratipaksha bhavana /distraction (PYS 2-33), asanas /postures(PYS 2-47, 48), pranayama / breathing techniques(PYS 2-52) and dhyana/meditation (PYS 2-53). Traditional scriptures explains human existence through panchakosha concept and all experiences and expressions are manifested in three domains - kaya /karma (behaviour / action) Scriptures, Vak (speech) and Manas (Mind).

Anger which originates in manomaya kosha (emotional body), percolates either direction and affects all koshas (gross body, energy body, intellectual body and bliss body). Anger manifestations occur as bodily expressions (behaviours, aggression, violence), speech expressions (verbal aggression, yelling, shouting etc) and passive expressions (hostility, suppression, resentful, withdrawal, revengeful etc).

Among the available handful of school based yoga studies on adolescent mental health, anger is studied only in a few studies that too as a subscale component. Improvement in anger scores was observed yoga group as against control group in all these studies (Vernon, 2003, Khalsa, 2011; Lisa, 2013; Joshua, 2015). Review studies on yoga education in schools calls for greater standardization and appropriateness of yoga intervention (Ferreira, 2015). 
Int.J.Curr.Res.Aca.Rev.2016; 4(12): 93-102

There is a lack of clarity among researchers on anger construct in terms of its definition, demarcation between hostility and aggression. Anger is a complex construct to assess considering non availability of specific bio-markers and also homeostatic levels of anger that are considered healthy. Research on practices derived from contemplative traditions, particularly Yoga has shown promising benefits on mental health, academic performance (Amit Kauts, 2009) and well-being (Simeon, 2003).

From the available literature it is evident that anger has received less importance as an independent variable and need for using appropriate yoga module and measurements for anger management in the school setting. Further rising Indian adolescent population and also the maladaptive behaviours of anger in schools and colleges (Alaka Mani, 2016) provides strong rationale for this proposed study.

\section{Methods and Materials}

\section{Design}

Pre-post control group study conducted in two English medium co-education high schools by administering yoga sessions as a part of curriculum. Yoga group received yoga intervention for a period of 4 months with 2 yoga sessions per week. Free periods were allotted to yoga group and hence waitlisted control group just attended the routine class and did not do any yoga during the study period. Both the schools had yoga group and control group. Anger is studied as a single parameter in this study. Assent, consent and approvals from children, parents and school authorities respectively were obtained in writing and the study was approved by the institutional ethical committee. Authorised tools and software were used for measurements and assessment.

\section{Sample}

In all, 187 children participated in the study with 114 children in yoga group and 73 in control group. Both girls and boys studying in $8^{\text {th }}$ standard with mean age of 13.3 participated in the study.

Eleven schools in south Bangalore were approached out of which three schools agreed to be part of the study. Majority of children in one school had difficulty in understanding English and filling up the questionnaires as their primary and middle school level education was in the local language medium. Only two schools Jyoti Kendriya Vidyalaya and Auden High School participated in the study.

Only high schools which had two or more sections of $8^{\text {th }}$ standard were considered for study. One school had only two sections and another school had four sections of $8^{\text {th }}$ standard. Using lottery method sections were allotted as yoga / control group. Students studying in $8^{\text {th }}$ standard and willing to participate in the study were included in the study while students who have severe physical impairment or medical conditions that interfere in administration of tools or the yoga intervention are excluded from the study.

\section{Yoga Module for Anger Management}

Integrated Approach Yoga Therapy (IAYT) based yoga module for anger management was used for the study. The module comprised of asanas, breathing techniques, meditation and knowledge points. The module was carefully developed to suit high school children, minimizing the religious 
aspects.The overall framework of the 30 minutes module is given below

Opening Prayer: 2 verses related to anger from Bhagavad Gita (2-61 \& 2-62)

Asanas: Dynamic practice of Surya Namasakara Ardhakati Chakrasana, Trikonasana, Parshwakonasana, Veerabhadrasana

Pranayama : Breathing awareness \& deep abdominal breathing

Meditation : Guided meditations for anger management. Anger management mechanisms were driven in the meditation. They include 1) Thinking and Feeling (awareness), 2) Art of sublimation (manaprashamana), 3) Pair of opposites (pratipaksha bhavana).

Knowledge points: Themes that drive concept of anger in Yama, Niyama (ahimsa, shoucha, aparigrahaetc) were driven throughout the sessions during gaps.

Tools: Anger was measured using two self reporting psychometric scales for anger.

1) Anger scale developed by the authors (KVM Anger Scale), with 23 items, measuring anger at Kayena (behavioural), Vacha(speech) and Manasa (Mental) domains.

2) State-Trait Anger Expression InventoryChild and Adolescents (STAXI 2 CA scale), a 35 item self-report scale that measures anger experience, expression and control in adolescents..

Written subjective feedback from the children and parents after completion of the intervention also served as a tool for assessment.
Statistical tool SPSS version 10 was used to conduct statistical analysis.

Procedure: Yoga classes were conducted as group sessions with medium of instruction as English by trained and certified yoga instructors during allotted academic hour. Children practiced yoga in their uniforms with waist belts loosened. Girls during menstrual cycle were refrained from practicing yogic postures but were present in the session. Children whose health condition did not permit practicing yoga postures on any particular session were asked to remain seated in the session. Attendance of intervention group was maintained.

Assent forms and consent forms from the parents were obtained for each participant. Institutional approval to conduct the study was also obtained.

Questionnaires were administered in the class rooms before commencement and after completion of the yoga intervention program. Children were briefed about the study and then asked to fill up the questionnaire were also instructed to answer all the questions.

Data processing: Raw scores of each subscale corresponding to each participant were converted into percentile scores and tscores with the help of conversion tables provided in the professional manual.

Percentile scores were used to calculate intensity of anger, gender difference and significance through multivariate analysis using General Linear Model; t scores were used to calculate correlation using bivariate Pearson product-moment correlation coefficients. 


\section{Analysis}

Total of 187 subject's data was considered for analysis which comprised of 114 children (55 boys and 59 girls) in yoga group and 73 children ( 33 boys and 40 girls) in control group. Further in all, there were 88 boys and 99 girls in the study. The age group of children was 13-14 years. The data was analysed using SPSS 10 software.

Anger assessment is done using two psychometric scales i.e. KVM Anger Scale and STAXI-2-CA scale. As the scales differ in subscales and domains of measurement data obtained from two scales were analysed separately.

\section{Analysis of data from KVM Anger Scale}

Reliability scores (Cronbach's Alpha coefficient) for the anger scale was observed at 0.812. Normality test confirmed normal distribution of pre data in both yoga and control groups.
Mean and Standard Deviation was calculated for yoga and control group both for pre data and post data. Significant reduction in mean scores in yoga group and a slight increase in the mean scores in the control group was observed as in Table 2. Paired t-test results of pre-post data of yoga group and control group is shown in Table 3.

From the table 3 it is observed that the yoga group showed significant change in the prepost scores confirming the effect of yoga intervention whereas there was no significant change observed in the control group. Table 2 shows significant reduction in anger scores in yoga group.

\section{STAXI 2 CA Scale}

The raw scores of five subscales were analyzed separately for yoga and control group. The mean and standard deviations are provided in table 4 :

\section{Table.1 Test of Normality for pre-data}

\begin{tabular}{|l|r|r|c|r|r|r|}
\hline \multirow{2}{*}{ Group } & \multicolumn{3}{|c|}{ Kolmogorov-Smirnov $^{\mathrm{a}}$} & \multicolumn{3}{c|}{ Shapiro-Wilk } \\
\cline { 2 - 7 } & Statistic & \multicolumn{1}{c|}{ df } & \multicolumn{1}{c|}{ Sig. } & Statistic & \multicolumn{1}{c|}{ df } & \multicolumn{1}{c|}{ Sig. } \\
\hline CG & .092 & 73 & $.200^{*}$ & .988 & 73 & .713 \\
\hline Yoga & .072 & 114 & $.200^{*}$ & .986 & 114 & .306 \\
\hline
\end{tabular}

Table.2 Mean \&SD, group wise

\begin{tabular}{|l|r|r|c|c|}
\hline & \multicolumn{2}{|c|}{ Pre-data } & \multicolumn{2}{c|}{ Post data } \\
\hline & Mean & SD & Mean & SD \\
\hline Yoga Group & 46.20 & 6.92 & 42.41 & 7.31 \\
\hline $\begin{array}{l}\text { Control } \\
\text { Group }\end{array}$ & 46.36 & 8.15 & 46.73 & 7.00 \\
\hline
\end{tabular}


Int.J.Curr.Res.Aca.Rev.2016; 4(12): 93-102

Table.3 Paired Samples Test

\begin{tabular}{|c|c|c|c|c|c|c|c|c|c|c|}
\hline \multirow{3}{*}{ Group } & \multirow{3}{*}{ Pair } & \multirow{3}{*}{ 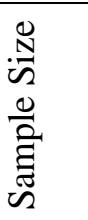 } & \multicolumn{5}{|c|}{ Paired Differences } & \multirow{3}{*}{$\mathrm{t}$} & \multirow{3}{*}{ df } & \multirow{3}{*}{$\begin{array}{l}\text { Sig. } \\
(2- \\
\text { tailed })\end{array}$} \\
\hline & & & \multirow[t]{2}{*}{ Mean } & \multirow[t]{2}{*}{ SD } & \multirow[t]{2}{*}{$\begin{array}{l}\text { Std. } \\
\text { Error } \\
\text { Mean }\end{array}$} & \multicolumn{2}{|c|}{$\begin{array}{l}95 \% \text { Confidence } \\
\text { Interval of the } \\
\text { Difference }\end{array}$} & & & \\
\hline & & & & & & Lower & Upper & & & \\
\hline Yoga Group & Pre - post & 114 & 3.789 & 6.992 & .655 & 2.49 & 5.09 & 5.79 & 113 & .000 \\
\hline Control Group & Pre - post & 73 & -.110 & 6.590 & .771 & -1.65 & 1.43 & -.142 & 72 & .887 \\
\hline
\end{tabular}

Table.4 Mean and SD of pre and post data of both groups

\begin{tabular}{|l|c|c|c|c|c|}
\hline & \multicolumn{2}{|c|}{ Pre Data } & \multicolumn{2}{c|}{ Post Data } & \multirow{2}{*}{ Sig } \\
\hline & Mean & SD & Mean & SD & \\
\hline State Anger - Yoga & 15.39 & 4.56 & 14.39 & 4.29 & 0.03 \\
\hline State Anger - Control group & 16.04 & 4.21 & 17.73 & 4.78 & 0.00 \\
\hline Trait Anger - yoga group & 19.73 & 4.12 & 18.46 & 4.33 & 0.00 \\
\hline Trait Anger - Control group & 20.00 & 4.48 & 20.96 & 4.32 & 0.07 \\
\hline Anger Out - Yoga group & 9.23 & 2.38 & 8.95 & 2.3 & 0.25 \\
\hline Anger Out - Control group & 9.88 & 2.4 & 9.84 & 2.32 & 0.89 \\
\hline Anger In - Yoga group & 8.98 & 2.33 & 9.13 & 2.33 & 0.47 \\
\hline Anger In - Control group & 9.36 & 2.52 & 9.4 & 2.31 & 0.9 \\
\hline Anger Control - Yoga group & 11.02 & 2.56 & 11.25 & 3.06 & 0.4 \\
\hline Anger Control - control group & 11.26 & 2.64 & 11.37 & 2.57 & 0.7 \\
\hline
\end{tabular}

There is a significant reduction in state and trait anger scores in yoga group while a significant increase in mean state anger scores were observed in control group. There is no significant change observed in anger out, anger in and anger control scores of yoga and control group.

\section{Conclusion}

Yoga is a holistic anger management program for children. Yoga education in high schools has great potential to improve mental health. The present work showed a statistically significant reduction of anger scores in yoga group which highlights the benefits of yoga education in schools for establishing the mental health. The results also report statistically significant increase in state anger scores in control group, which is a cause of concern.
The work also underscores the holistic approach of yoga emphasizing yama, niyama in addition to popular asanas and pranayams. The meditation developed received very encouraging subjective feedback.

Adolescence is the right age to drive the moral education and imbibe positive behavioural and attitudinal components. The traditional gurukul system stress on the moral education and character building in addition to imparting knowledge. The convocation address in Shiksha Valli, Thaitiriya Upanishad is a classic example of this approach. Accordingly the present study focused on moral education focusing anger management techniques driven through meditations. 
Anger management in adolescence using cognitive-behavioural therapy (Denis GS, 2004), social-skill training (Selahattin, 2012, Herrmann, 2003) and psycho educational programs (Kristin, 2005) are studied in various clinical and non-clinical settings. However, school-based programs are less in numbers and are multi-component in nature. Meta-analysis on school based anger management programs and review studies (Graham, 2005) report low sample size, multiple measures and lack of clarity in methodology as limitations.

The present study was designed and focused on objective parameters. However, during implementation, a lot of subjective, attitudinal and behavioural changes were noticed by the investigator, teachers and parents. Future studies are recommended to observe, record and analyses the subjective feedback during yogic interventions.

Since the study was done during academic hours, school authorities insisted to consider section wise grouping of yoga and control group. Hence randomization was done only at selecting sections and not at subject level. Secondly, the control group was passive and was not assigned any activity. Future studies are recommended with randomization at subject level. Also future studies could be carried out with assessment of anger using physiological parameters.

\section{Acknowledgement}

Authors gratefully acknowledge Sri. Venkateswara Vedic University, Tirupati who have funded this study. Authors also acknowledge schools who participated in the study - Jyothi Kendriya Vidhyalaya and Auden High School. Special acknowledgement to Dr. Thomas Brunner, one of the authors of STAXI 2 CA scale who shared the scale and the professional manual free of cost. Special thanks to Mr. Govinda A, who helped a lot in getting the scientific papers.

\section{References}

Alaka Mani, T.L., Manoj Kumar Sharma, Marimuttu, P., Omkar, S.N., Nagendra, H.R. 2016. Anger assessment among high school children, Int. J. CMPR, Vol. 2, Issue, 8 pp.585-590.

Amit Kaut, Neelam Sharma. 2009. Effect of yoga on academic performance in relation to stress, Int. J. Yoga, 2009 Jan-Jun; 2(1): 39-43. doi: 10.4103/0973-6131.53860, PMCID: PMC3017967

Beata, P., Emilia Potembska, MaciejZygo, Marcin Olajossy, Ewa Dziurzyńska. 2016. Prevalence of self-injury performed by adolescents aged 16 19 years, Psychiatr. Pol., 50(1): 29-42,

Bethany, B., Marina Ebert, Shirley Telles, Sat Bir S., Khalsa. 2015. School-based Yoga Programs in the United States: A Survey, Adv. Mind Body Med., 29(4): 18-26.

Catherine, P.B., Bradshaw, Cindy M. Schaeffer, Hanno Petras, Nicholas Ialongo. 2015 Predicting Negative Life Outcomes from Early Aggressive - Disruptive Behavior Trajectories: Gender Differences in Maladaptation Across Life Domains; J. Youth Adolescence, 39:953-966, DOI 10.1007/s10964-009-9442-8

CDC. 2015. Fact-sheet 2012 of Centre for Disease Control and Prevention; Understanding youth violence, 1-800CDC-INFO (232-4636), www.cdc.gov/violenceprevention

Chaya, M.S. Mayasandra, S., Chaya, H.R. Nagendra, Sumithra, S., Anura, K. and K. Srinivasan.2012. Effect of Yoga on Cognitive Abilities In Schoolchildren 
from a Socioeconomically

Disadvantaged Background: A

Randomized Controlled Study; The J. Alternative and complementary med., Volume 18, Number 12, 2012, pp. 1-7

Collen, A.Q., Colleen, A., Quinn, David, Rollock, and Scott, R. 2015. Vrana 'A Test of Spielberger's State-Trait Theory of Anger with Adolescents: Five Hypotheses' NIH Public Access, Emotion, $\quad 14(1)$ : $\quad 74-84$. doi:10.1037/a0034031.

Cornell, D.G., Cornell, D.G., Peterson, C.S., Richards, H. 1999. Anger as a predictor of aggression among incarcerated adolescents, J. Consult Clin. Psychol., 67(1):108

Coskun ArslAn. 2009. Anger, Self-esteem, and Perceived Social Support in Adolescence; Social Behavior and Personality, 2009, 37(4), 555-564

Dahlberg, L.L., Mercy, J.A. 2009. History of violence as a public health issue. Centre for Disease Control, AMA Virtual Mentor, February 2009. Volume 11, No. 2: 167-172.

Dale, J. Terasaki, BizuGelaye, Yemane Berhane and Michelle, A. Williams. 2009. Anger expression, violent behavior, and symptoms of depression among male college students in Ethiopia', BMC Public Health, 9: 13 doi:10.1186/1471-2458-9-13.

Das, J.K., Jai, K. Das, Rehana, A.S., Zohra, S.L., Marium, N.K., Wajeeha, M., Vikram, P., and Zulfiqar, A.B. 2016. Review article - Interventions for Adolescent Mental Health: An Overview of Systematic Reviews; J. Adolescent Health, 59: S49eS60.

Denis, G.S., Howard Kassinove, Bernard, S. Gorman. 2003. Cognitive-behavioral therapy for anger in children andadolescents: A meta-analysis; Aggression and Violent Behavior, 9: 247-269.
Donna Wang and Marshall Hagins. 2016. Perceived Benefits of Yoga among Urban School Students: A Qualitative Analysis; $\quad$ Evidence-Based Complementary and Alternative Med., Article ID 8725654, 7 pages http://dx.doi.org/10.1155/2016/872565 4.

Ferreira-Vorkapic, C., J.M. Feitoza, M. Marchioro, J. Simões, E. Kozasa and S. Telles. 2006. Are There Benefits from Teaching Yoga at Schools? A Systematic Review of Randomized Control Trials of Yoga-Based Interventions; Evidence-Based Complementary and Alternative Med., Article ID 345835, 17 pages.

Graham Glancy, Michael, A. Saini. 2005. An Evidenced-Based Review of Psychological Treatments of Anger and Aggression; Research Commentary, Brief Treatment and Crisis Intervention, 5.

Herrman, D. Scott, Mc Whirter, J. Jeffries. 2012. Anger \& aggression management in young adolescents: an experimental validation of the SCARE program;

http://www.freepatentsonline.com/ article/ Education-TreatmentChildren/107801232.html

Ingunn Hagen, Usha, S., Nayar. 2014. Yoga for children and young people's mental health and well-being: research review and reflections on the mental health potentials of yoga; Frontiers in Psychiatry, Volume 5 | Article 35 | 1

Jennie Hejdenberg, Bernice Andrews. 2011. The relationship between shame and different types of anger theory-based investigation; Personality and Individual Differences, 50: 12781282.

Joshua, C. Felver, Bethany Butzer, Katherine J. Olson, Iona M. Smith, and Sat Bir S. Khalsa. 2015. Yoga in 
public school improves adolescent mood and affect; Contemp Sch Psychol., 19(3): 184-192. doi: 10.1007/s40688-014-0031-9.

Jungmeen Kim-Spoon, Christopher Holmes and Kirby Deater-Deckard. 2015. Attention regulates anger and fear to predict changes in adolescent risktaking behaviors; J. Child Psychol. Psychiatry.

Kathryn Puskar, DianxuRen, Lisa Marie Bernardo, Tammy Haley and Kirsti Hetager Stark. 2008. 'Anger correlated with psychosocial variables in rural youth, Compr. Pediatr. Nurs.

Khalsa, Sat Bir, S., Khalsa, Lynn HickeySchultz, Deborah Cohen, Naomi Steiner, Stephen Cope. 2011. Evaluation of the Mental Health Benefits of Yoga in a Secondary School: A Preliminary Randomized Controlled Trial; J. Behavioral Health Services \& Res.

Kristin, A. Gansle. 2005. The effectiveness of school-based anger interventions and programs: A meta-analysis, J. School Psychol., 43: 321-341.

Laura Santangelo White. 2009. Yoga for Children; Pediatric Nursing, Vol. 35/No. 5.

Laura Santangelo White. 2010. Reducing Stress in School-age Girls Through Mindful Yoga; J. Pediatric Health Care, number 1, doi:10.1016/j. pedhc.2011.01.002.

Lisa, A.C., Jessica, J.N., Jessica, L.F., Ravi, S.K,. Sat Bir, S. Khalsa. 2005. Qualitative Evaluation of a high school yoga program: feasibility and perceived benefits; Explore, Vol. 9, No. 3.

Michael, J., Furlong. 2012. Introduction to Special Issue School-Based Approaches to Promote Complete Mental Health: School Psychologists Working to Foster Students' Thriving
Well-being, Contemp School Psychol., 19: 231-232; DOI 10.1007/s40688015-0078-2

Miron Ehud, Bar Doy An, Strulov Avshalom. 2010. Here and now Yoga in Israeli schools, Int. J. Yoga, 3(2): 42-47. doi: 10.4103/09736131.72629, PMCID: PMC2997231

Munni, Malhi, P. 2006. Adolescent violence exposure, gender issues and impact. Indian Paediatr., 43(7): 607-612.

Pullen, L., Modrcin, M.A., McGuire, S.L., Lane, K., Kearnely, M., Engle, S. 2015. Anger in Adolescent Communities: How Angry Are They? Pediatr. Nurs., 41(3): 135-40.

Ronald, C. Kessler et al., 2008. Childhood adversities and adult psychopathology in the WHO World Mental Health Surveys; The British J. Psychiatry BJP, 197: 378-385.

Ronald, C. Kessler, G. Paul Amminger, Sergio Aguilar-Gaxiola, Jordi Alonso, Sing Lee, and T. Bedirhan Ustun. 2007. Age of onset of mental disorders: A review of recent literature, Curr. Opin. Psychiatry, 20(4): 359-364.

Rowell, L. Huesmann, Leonard, D. Eron, Eric, F. Dubow. 2012. Childhood predictors of adult criminality: are all risk factors reflected in childhood aggressiveness?; Criminal Behaviour and Mental Health, 12, 185-208 2002 (C) Whurr Publishers Ltd

Selabattin, A., Coskun Arslan, M. Engin Deniz. 2012. Analysis of anger management in terms of social skills; African J. Business Management, Vol. 6(11), pp. 4150-4157.

Shirley Telles. 2012. Effect of Yoga on Mental Health in children, editor, Child and Adolescent Mental Health. New Dehli: Sage Publications; (2012). p. 219-27. 
Simeon, P., Slovacek, Susan, A., Tucker, Laura Pantoja. 2003. A Study of the Yoga Ed Program at The Accelerated School, Program Evaluation \& Research Collaborative (PERC).

Simona, V.C., Sebastian, P., Daniel, D. 2012. The relationship of anger and cognitive distortions with violence in violent offenders population; A Meta Analytic Review; The European J. Psychol. Appl. legal context, 4(1): 5977.

Stephanie, S. Daniel, Franklin, David, B. Goldston, Alaattin Erkanli, Joseph, C. and Andrew, M. Mayfield. 2009. Trait Anger, Anger Expression, and Suicide
Attempts among Adolescents and Young Adults: A Prospective Study, J. Clin. Child Adolesc. Psychol.

Vernon, A. Barnes, Lynnette, B. Bauza and Frank, A. Treibe. 2003. Impact of stress reduction on negative school behavior in adolescents; Health and Quality of Life Outcomes, 1.

Zimmer-Gembeck, M.J., Skinner, E.A. 2015. 'Adolescent vulnerability and the distress of rejection: Associations of adjustment problems and gender with control, emotions, and coping' J. Adolesc., 5:149-59.

\section{How to cite this article:}

Alaka Mani, T.L., M.K. Sharma, P. Marimuttu, S.N. Omkar and Nagendra, H.R. 2016. Yogic Management of Anger in High School Children. Int.J.Curr.Res.Aca.Rev.4(12): 93-102. doi: http://dx.doi.org/10.20546/ijcrar.2016.412.009 